\title{
Appropriate terminology in the nomenclature of the color vision deficiency
}

\author{
Burak Turgut* and Feyza Çaliş Karanfil \\ Department of Ophthalmology, Faculty of Medicine, Yuksek Ihtisas University, Ankara, Turkey
}

\begin{abstract}
The colour vision deficiencies (CVDs) are visual disorders occuring in the absence or abnormal function of one or more cones. Although the term "Color blindness" has been used to describe CVDs, it is actually a wrong term for nomenclature. It seems that "color vision deficiency sould be correct term for this disorder because color blindness means the absence of the ability to detect or distinguish any color. CVDs include various mild or heavy, and hereditary or acquired color vision deficids. In this review, we aimed to summarize the CVDs.
\end{abstract}

Human retina has two types of photoreceptors including rods, which are responsible for vision in dark; and cones, which are responsible for vision in bright light and colour vision. There are three types of cones including the long-wavelength cones (L-cones, sensitive to red color) with peak sensitivity at $560 \mathrm{~nm}$; the medium-wavelength cones (M-cones, sensitive to green color) with peak sensitivity at 530 $\mathrm{nm}$; and the short-wavelength cones (S-cones, sensitive to blue color) with peak sensitivity at $430 \mathrm{~nm}$. The photon absorptions in different levels by three different cones provide the brain to discriminate colour. People with normal color vision are known as normal trichromats, and normal colour perception is also known as trichromacy [1-4]. The colour vision deficiency (CVD) occurs in the absence or abnormal function of one or more cones [5-7].

Color blindness is a term which has been used to describe the CVDs. However, it is wrong nomenclature. Correct term should be "color vision deficiency (CVD)". Because, the term "color blindness" means the absence of the ability to detect or distinguish any color [5-7].

Daltonism is derived from the name of first scientist John Dalton (1766-1844) who recognized and published his and his brother's redgreen CVD in the first scientific paper [8].

Color vision deficiencies are mainly divided into two groups as hereditary and acquired CVDs. In Table 1, the main specifications of hereditary and acquired CVDs have been given.

Dyschromatopsia (dys-disorder+chrōma-color+opsis-vision): A general term using description of especially acquired CVDs [1-8].

Defective color vision: A general term using description of especially congenital or genetic CVDs in which persons can not exactly and correctly perceive and detect as that in normal population [1-8].

Achromatopsia (a-absence+chroma-color+opsis-vision) (Complete color blindness, rod monochromacy, rod monochromatism): A term which "color blindness" should be used to call for "the cases with acromatopsia or achromatosis, real or true color blindness, which perceive all objects around in the color of the grey color and its various hues. The subjects with achromatopsia are typically totally color blind, and they have no ability to distinguish colors in the different wavelength. These subjects have only the rods, and the cone receptors are completely absent [1-8].

Dichromatism (di-two+chromat-color) (Dichromacy): A term describing the persons having only two different types of functional color receptors and having protanopia or deuteranopia or tritanopia [1-7].

Trichromatism (tri-three+chromat-color) (Trichromacy) (Normal color vision): A term describing the persons having three different types of color (red, green and blue) receptors and having normal color vision [1-8].

Anomalous trichromatism (anomalous trichromacy): A term describing color vision deficiency (protanomaly or deuteranomaly or tritanomaly) in some color due to the decreasing or increasing in sensitivity of one or more different types of color receptor despite to have all three functional cones. Anomalous trichromats recognize the colors in different intensity of each primary colour as compared with a normal trichromat [1-10].

\section{Red-green CVD}

The most common CVD (over 90\%) involving either L-cones or M-cones, and affecting usullay men (1/12 in men and 1/200 women for red-green colour vision deficiency). People with red-green colour deficiency confuse colours in the red-yellow-green spectra [1-10].

Protanopia/Protanopic (red-blind): The red sensitive cones (L-cones) are absent. Protanopia is usually an inherited CVD and exists in almost $1 \%$ of the males. It is a severe type of CVDs. The subjects with protanopia can only perceive light wavelengths between $400-650 \mathrm{~nm}$

Correspondence to: Burak Turgut, MD, Professor of Ophthalmology, Department of Ophthalmology, Faculty of Medicine, Yuksek Ihtisas University, 06520, Ankara, Turkey, Tel: +90 312 2803601; Fax: +90 3122803605; E-mail: burakturgut@yiu.edu.tr

Key words: color vision deficiency, defective color vision, color blindness, daltonism, color vision defects

Received: October 03, 2017; Accepted: October 25, 2017; Published: October 27,2017 
Table 1. The comparative main specifications of hereditary and acquired color vision deficiencies.

\begin{tabular}{|c|c|}
\hline Hereditary color vision deficiency & Acquired color vision deficiency \\
\hline $\begin{array}{l}\text { - Present at birth } \\
\text { - Always bilateral and equal } \\
\text { - Red-green deficiency (Protanopia or } \\
\text { Deutanopia) } \\
\text { - High involvement in Males ( } 3-8 \% \text { vs } 0.5 \% \text { in } \\
\text { female to European, Asian or African races) } \\
\text { - Visual acuity is usually not affected except } \\
\text { monochromatism (no visual field defect) } \\
\text { - Stable in severity and type througout life } \\
\text { - X-linked recessive trait } \\
\text { - Female just carrier, Male usually patient }\end{array}$ & $\begin{array}{l}\text { - Onset after birth } \\
\text { - Generally unilateral or assymmetrical } \\
\text { - Blue-yellow deficiency (Tritanopia) } \\
\text { - Equal involvement in both sexual } \\
\text { - Associated deficiency in visual acuity, } \\
\text { visual field and other visual functions } \\
\text { - Stabilization depends on underlying } \\
\text { ethiology and severity and type can vary } \\
\text { - Secondary to ocular/systemic diseases or } \\
\text { medications }\end{array}$ \\
\hline
\end{tabular}

but not over $700 \mathrm{~nm}$. They can perceive pure reds as black, and can not distinguish purple colours from blues. Additionally, these subjects perceive orange-tinted reds as very dim yellows and all orange-yellowgreen as a similar yellow hue [1-10].

Protanomaly/Protanomalous: It describes defective or weak redvision and a less severe type of CVDs. The subjects with this CVD can discrimine poorly red from green color and also different shades of the same colour in the red-yellow-green spectrum from each other [1-10].

Deuteranopia/Deuteranopic (green-blind): This type of dichromatism describes the fact that green sensitive cones (M-cones) are absent. Deuteranopes have only two cone pigments. This CVD is also usually hereditary and sex-linked [1-10].

Deuteranomaly/Deuteranomalous: It describes defective or weak green-vision. Deuteranomaly is a less severe hereditary and sexlinked form of red-green CVD. This CVD mildly affecting red-green hue discrimination is seen in 5\% of European males, and is due to an anomalous shift in the green-sensitive cones and characterized by the problems of discrimination different shades of the same colour in the red-yellow-green spectrum [1-10].

\section{Blue-yellow CVD [1-10]}

Tritanopia/Tritanopic (blue-blind): It describes the fact that blue sensitive cones (S-cones) are absent, a rare deficiency related to Chromosome 7, no relation with the sex chromosomes, equal prevalence in both sexual, blue color seems greenish, yellow and orange seem pinkish and purple colour seems deep red [1-10].

Tritanomaly/Tritanomalous: It means defective or weak bluevision [1-10].

Hereditary CVD: The inherited color vision deficiency which is usually caused by X-linked recessive gene, which is passed from a mother to her son $[7,9,10]$.

\section{Acquired CVDs}

Ocular disease related acquired CVD: Secondary color vision deficiency is related to damages of the optic nerve or retina because of various diseases and injuries $[3,5,7,9]$. This form of CVD has three types:

Type 1 red-green acquired CVD have protan CVD characteristics. Progressive cone dystrophies and retinal pigment epithelium dystrophies are in this class $[3,5,7,9]$.

Type 2 red-green acquired CVD have deutan CVD characteristics with greater reduction in short-wavelength sensitivity and a milder blue-yellow loss. Optic neuritis is included into this class [7,9].

Type 3 blue-yellow CVD characteristics (tritan CVD). It may be accompanied by a shift of maximum luminance sensitivity to shorter wavelengths (pseudo-protanomaly; central serous chorioretinopathy and age-related macular degeneration) or not (rod and rod-cone dystrophies, retinal vascular disorders, peripheral retinal degenerations, glaucoma and autosomal dominant optic atrophy-Kjer optic atrophy) $[3,5,7,9]$.

Early glaucoma may be presented with acquired tritan CVD while as advanced glaucoma may be associated with acquired protan-deutan CVDs $[3,5,7,9]$.

Acquired blue-yellow CVDs may be related to the changes of ocular media such as cataract or changes associated aging in crystalline lens and diseases affecting choroid and the outer retinal layers. Acquired red-green CVDs may be resulted of the diseases of optic nerve and inner visual pathway $[3,5,7,9]$.

Retinopathies cause often tritan or blue-yellow CVD while as optic neuropathies (traumatic or toxic) cause red-green CDVs. The causes of acquired CVD secondary to ocular and extraocular diseases except for aging include diabetes mellitus, glaucoma, macular degeneration, Alzheimer's disease, Parkinson's disease, multiple sclerosis, chronic alcoholism, leukemia, and sickle cell anemia $[3,5,7,9]$.

Medication related blue-yellow acquired CVD: It may be cause to the usage of chloroquine, indomethacin, phenothiazine, thioridazine, tridione, digoxin and PDE5-inhibitors [3,5,7,9]

Medication related red-green acquired CVD: It may be related to MAO-inhibitors and ethambutol $[3,5,7,9]$.

\section{Acknowledgments}

Conflict-of-interest statement: The authors declare that there is no conflict of interest regarding the publication of this paper.

Funding: The authors received no financial support for the research, authorship, and/or publication of this article.

\section{References}

1. Swanson WH, Cohen JM (2003) Color vision. Ophthalmol Clin North Am 16: 179-203. [Crossref]

2. De Valois KK, De Valois RL (2000) Color Vision. In: De Valois KK, editor. Seeing California: Academic Press, 129-170.

3. Sample PA, Weinreb RN, Boynton RM (1986) Acquired dyschromatopsia in glaucoma Surv Ophthalmol 31: 54-64. [Crossref]

4. Neitz M, Neitz J (2000) Molecular genetics of color vision and color vision defects. Arch Ophthalmol 118: 691-700. [Crossref]

5. Simunovic MP (2010) Colour vision deficiency. Eye (Lond) 24: 747-755. [Crossref]

6. Remmer MH, Rastogi N, Ranka MP, Ceisler EJ (2015) Achromatopsia: a review. Curr Opin Ophthalmol 26: 333-340. [Crossref]

7. Hasrod N, Rubin A (2016) Defects of colour vision: A review of congenital and acquired colour vision deficiencies. Afr Vision Eye Health 75: a365.

8. Ugalahi MO, Fasina O, Ogun OA, Ajayi BG (2016) Prevalence of congenital colour vision deficiency among secondary school students in Ibadan, South-West Nigeria. Niger Postgrad Med J 23: 93-96. [Crossref]

9. Dalton J (1798) Memoirs of the Literary Philosophical Society of Manchester (Mem Literary Philos Soc Manchester). Extraordinary facts relating to the vision of colours: with observations. London: Cadell and Davins. 5: 28-45.

10. Simunovic MP (2016) Acquired color vision deficiency. Surv Ophthalmol 61: 132-155 [Crossref]

Copyright: (C2017 Turgut B. This is an open-access article distributed under the terms of the Creative Commons Attribution License, which permits unrestricted use, distribution, and reproduction in any medium, provided the original author and source are credited. 